\title{
CARDIO-AORTIC INVOLVEMENT IN CONGENITAL SYPHILIS WITH CO-EXISTENT RHEUMATIC HEART DISEASE
}

BY

\author{
F. J. T. BOWIE AND R. G. SIMPSON
}

From the Royal Infirmary, Aberdeen

A familiar and not uncommon clinical problem is provided when a patient presents with signs of aortic incompetence together with a history, of rheumatic fever and a positive serological test for syphilis. The cause of the aortic valve lesion usually rests between syphilis and rheumatism, and the diagnosis will swing in one direction or the other according to the presence or absence of collateral signs of the respective diseases. If such a patient also shows unequivocal evidence of mitral stenosis, the cause of the combined lesions may reasonably be attributed to rheumatic heart disease. Likewise, the co-existence of an aneurysm of the thoracic aorta and aortic incompetence strongly suggests a comprehensive diagnosis of cardio-aortic syphilis. Occasionally, the possibility of combined syphilitic and rheumatic heart disease must be considered, albeit such a combination is uncommon.

The essential features of the case to be described were aortic regurgitation, fusiform aneurysm of the ascending aorta and a persistently positive blood Wassermann reaction. A diagnostic exercise was set by the fact that the aortic valve lesion became manifest about two months after an attack of rheumatic fever, the aneurysm being detected for the first time 18 years later. Further, the patient was known to be a subject of congenital syphilis.

\section{Case Report}

The patient, a former electricity inspector, 38 years of age, was admitted to Aberdeen Royal Infirmary in 1949, on account of exacerbation of pain from chronic duodenal ulceration. Symptoms of dyspepsia first appeared at the age of 19 years, followed a few months later by an acute perforation, which was treated by surgical repair and gastroenterostomy. The ensuing years of reasonably good health were interrupted by bouts of ulcer dyspepsia which in recent months had become more troublesome.

Past History. At the age of 19 years, in 1930, the patient was admitted to a hospital in Aberdeen on account of pyrexia, joint pains, and nodular erythema of the extremities, of some three weeks' duration. A diagnosis of rheumatic fever was made, and the symptoms settled promptly during salicylate therapy. About two months later clinical evidence of aortic insufficiency was detected. Less than one year after the first rheumatic episode, he was re-admitted to the same hospital, because of similar symptoms; these responded as before to treatment with salicylates. Clinical signs of aortic incompetence were still present, and an X-ray film of the chest was reported as showing a normal heart shadow. In 1944, the patient was admitted to hospital because of dyspeptic symptoms and was diagnosed as chronic duodenal ulcer and aortic incompetence. An X-ray report stated: " Moderately severe enlargement of left ventricle and an aortic arch of normal appearance." Systematic interrogation disclosed that since 1944 or thereby there had been gradually increasing effort dyspnoea and palpitations; there had also been paroxysms of breathlessness at night during recent months. The family history, as obtained at the time of admission, disclosed nothing remarkable. The patient had been married for 3 years and his wife and three young children enjoyed good health.

Physical examination. The patient was well-developed and well-nourished and did not look ill. The temperature was $98.4^{\circ} \mathrm{F}$., the pulse rate 90 , and the respiration rate 20 per minute. Apart from a number of fine radiate scars above the upper lip, the face, skin, head, nose, ears, and mouth showed nothing of note. Eye movements, pupils and optic fundi were normal. The trachea was in the mid-line. Both sides of the chest expanded equally, and the percussion notes and breath sounds were normal. The radial pulses were equal and regular and were of the "water-hammer" type, and the blood pressure was 145/50. The apex 
beat was in the sixth interspace, outside the mid-clavicular line, and had a heaving quality. A faint and localized pulsation was felt in the second right interspace close to the sternum; from that site a grade-two systolic murmur was conducted upwards towards the neck, and a blowing diastolic murmur downwards alongside the sternum. A low-pitched diastolic rumble was heard in the region of the apex beat. There were no signs of congestive heart failure. The liver, spleen, and kidneys could not be palpated. The genitalia were normal, and detailed examination of the nervous system did not reveal any significant abnormalities.

Laboratory studies. The blood Wassermann and Kahn reactions were strongly positive on several occasions. Spinal fluid obtained by lumbar puncture showed normal cytology.and chemiştry and gave a negative Wassermann reaction. The urine was free from albumin and sugar and there was no organized deposit. The electrocardiogram was normal.

Radiological findings. A barium meal showed gross deformity of the duodenal cap and an ulcer crater. Plain films and screen examination of the chest showed enlargement of the left ventricle and an aneurysmal bulging of the ascending portion of the aortic arch, with some linear calcification (Fig. 1) and very obvious pulsation. The only deformity or displacement of the oesophagus shown by a barium swallow was that caused by an enlarged aorta.

Clinical diagnosis: Chronic duodenal ulcer; aortic aneurysm (luetic); aortic regurgitation (? rheumatic ? luetic). At this juncture the patient was seen by one of us (F.B.) in consultation and, as a result of this, the following additional information was disclosed.

Synopsis of luetic history. During the patient's first episode of rheumatic fever in 1930, a routine blood Wassermann test was found to be strongly positive. There was at that time no history or other evidence of

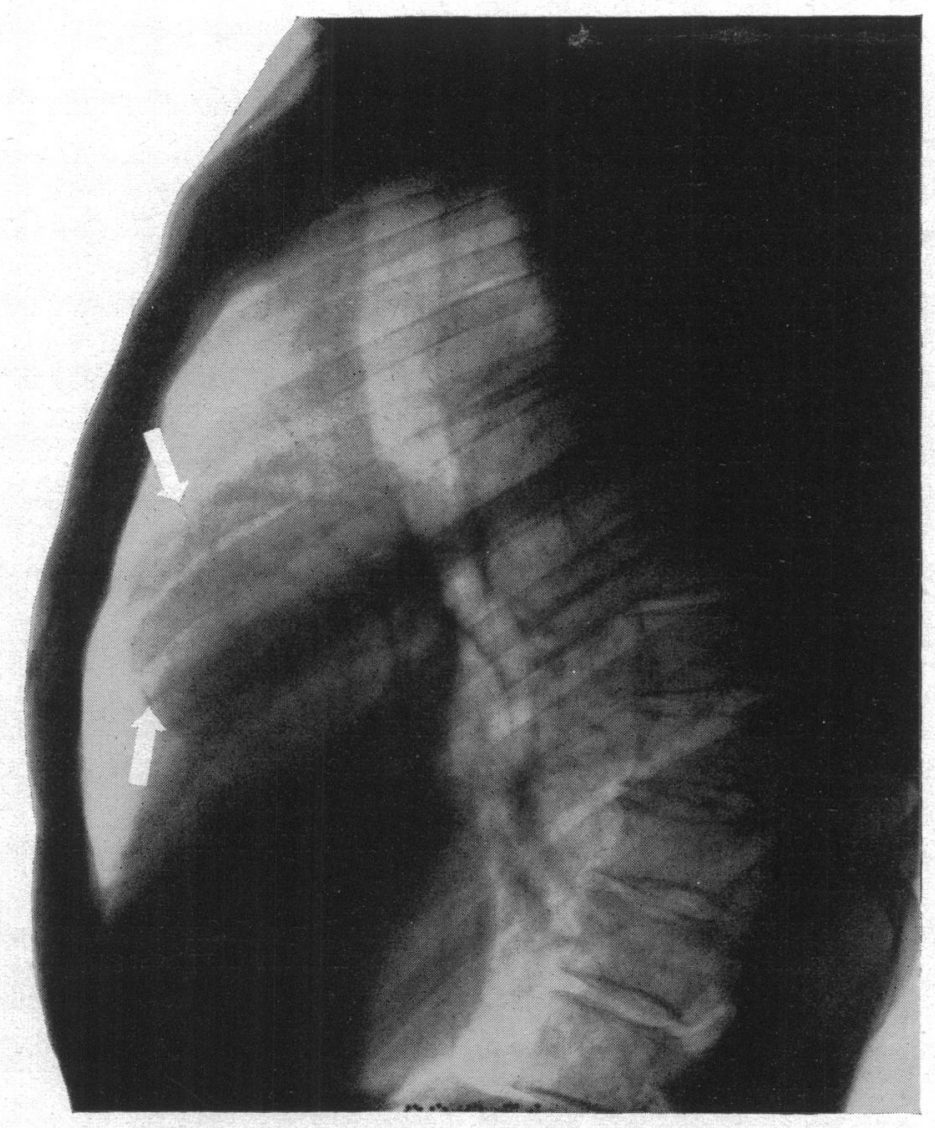

FIG. 1.-Radiogram showing aneurysm and linear calcification in ascending aorta. Right lateral view. 
acquired infection and no knowledge of syphilis in the patient's family. There were no unequivocal signs of congenital syphilis, but the incisor teeth were rather small and deformed and there were circumoral rhagades. A diagnosis of congenital lues was made on the grounds of a repeatedly positive blood reaction in a youth of 19 with no evidence of acquired disease and with stigmata suggestive of congenital infection. Treatment was commenced with injections of bismuth, and was carried on intermittently until 1937, eight courses in all being given. The blood Wassermann reaction remained strongly positive throughout that period. The patient defaulted in 1938 and returned to the Clinic in 1942 with acute gonorrhœa. The blood Wassermann was still strongly positive, and treatment was resumed with a course of mercury sulphide, but he defaulted again a few months later and did not return.

Further evidence in support of the diagnosis of congenital syphilis has recently been obtained from case records which show that the patient's father, then aged 33, attended at the Clinic in the year 1917 for treatment of late syphilis; he defaulted in the following year, but returned for further treatment in 1932 . The patient's sister, his only sibling and by three years his elder, is a known subject of congenital syphilis; she has been married for 22 years, and has a married daughter aged 21 years. Nothing is known about the patient's mother beyond the fact that she left the home in 1917 never to return. The patient himself has been twice married: the first marriage lasted from 1933 to 1941 and was sterile; in 1946 he married a widow who has presented him with three healthy offspring, whose present ages range from four months to four years.

\section{Discussion}

A stand must be taken upon the two issues which are in debate. The first concerns the cause of the aortic valve defect; the presumption of a rheumatic origin is based on the history of two attacks of rheumatic fever in youth and the development of auscultatory evidence of aortic regurgitation two months after the initial episode.

The second issue concerns the cause of the aortic aneurysm and demands more detailed consideration. Strong evidence is necessary to enable one to decide which of the two diseasesrheumatism or congenital syphilis-was responsible for the aortic lesion, since both are generally regarded as rare and disputable causes of aneurysm. Such evidence is provided by the radiograms which showed linear calcification in the walls of the aneurysm, a condition indicative of syphilitic aortitis. According to Shanks and Kerley (1951) calcified plaques in the ascending aorta are diagnostic of syphilis, a view which has been confirmed in recent years by the extensive clinical, pathological, and radiological investigations of several American authors (Jackman and Lubert, 1945; Leighton, 1948; and Thorner et al., 1949). The significance of this sign is further enhanced when calcification is absent from other portions of the aorta, and when the subject is less than fifty years of age. Calcification tends to occur in those cases where syphilis is of long duration, and consequently indicates relatively mild and very chronic aortitis. It is concluded that the weight of evidence in the present case is sufficient to permit a clinical diagnosis of combined chronic rheumatic and congenital syphilitic heart disease.

\section{Summary}

The case is described of a man, aged 38 years, with signs of aortic incompetence and of thoracic aortic aneurysm. Evidence is adduced whereby the aortic valve lesion is attributed to rheumatic heart disease, the aneurysm to congenital syphilis.

Linear calcification of the ascending portion of the aorta has been demonstrated radiologically, and the significance of this sign is discussed.

We wish to thank Professor H. W. Fullerton, Physician, Aberdeen Royal Infirmary, for permission to publish this case. We are also indebted to Miss Grace Barclay, Woodend Hospital, for the photographic reproduction.

\section{REFERENCES}

Jackman, J., and Lubert, M. (1945). Amer. J. Roentgenol., 53, 432.

Leighton, R. S. (1948). Radiology, 51, 257.

Shanks, S. C., and Kerley, P. (1951). Text-book of X-ray Diagnosis (Vol. 2). 2nd ed., London.

Thorner, M. C., Carter, R. A., and Griffiths, G. C. (1949). Amer. Heart J., 38, 649. 